\title{
Analysis of Longitudinal Timber Beam Joints Loaded with Simple Bending
}

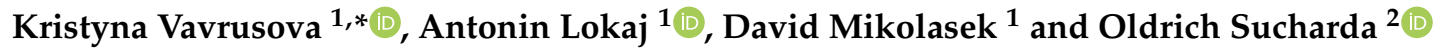 \\ 1 Department of Structures, Faculty of Civil Engineering, VSB-Technical University of Ostrava, \\ 70800 Ostrava-Poruba, Czech Republic; antonin.lokaj@vsb.cz (A.L.); david.mikolasek@vsb.cz (D.M.) \\ 2 Department of Building Materials and Diagnostics, Faculty of Civil Engineering, VSB-Technical University \\ of Ostrava, 70800 Ostrava-Poruba, Czech Republic; oldrich.sucharda@vsb.cz \\ * Correspondence: kristyna.vavrusova@vsb.cz; Tel.: +420-599-321-375
}

Received: 6 October 2020; Accepted: 4 November 2020; Published: 9 November 2020

\begin{abstract}
The joints in timber structures are often the decisive factor in determining the load-bearing capacity, rigidity, sustainability, and durability of timber structures. Compared with the fasteners used for steel and concrete structures, fasteners for timber structures generally have a lower load-bearing capacity and rigidity, with the exception of glued joints. Glued joints in timber structures constitute a diverse group of rigid joints which are distinguished by sudden failure when the joint's load-bearing capacity is reached. In this contribution, the load-bearing capacity of a longitudinal joint for a beam under simple flexural stress is analyzed using glued, double-sided splices. Joints with double-sided splices and connecting screws were also tested to compare the load-bearing capacity and rigidity. A third series of tests was carried out on joints made using glued double-sided splices augmented with screws. The aim of this combined joint was to ensure greater ductility after the load-bearing capacity of the glued splice joint had been reached.
\end{abstract}

Keywords: timber; joint; screw; glued; adhesive; bending strength; sustainability

\section{Introduction}

Timber use in the building industry has grown because of its sustainability, great material properties, and renewability. This has brought new trends, not only in the field of innovative wood-based materials but also the joining of the timber structure elements. The joints in timber structures are often the decisive factor in determining the load-bearing capacity, rigidity, and durability of timber structures.

Besides commonly used connections in the building industry for joining timber elements, the second largest group consists of connections used for the reconstruction of timber structure elements-for its strengthening or for the replacement of damaged sections of wood. Replacement of damaged sections is typical for beams loaded mostly with bending. For these joints it is possible to use either glued joints or joints with steel fasteners.

Glued-in steel rods or plates are also commonly used in glued joints. Some specialists from all around the world [1-3], including the Czech Republic [4-6], are dedicated to improving the capacity and performance of joints in timber structures using glued-in steel rods and plates [7].

A second option is joints with glued outer splices (wood, wood-based, and steel). The load-bearing capacity and deformation of these joints are influenced by considerably more factors than in the case of glued-in steel rod or plate joints [8]. Factors mainly include the type of wood species, adhesive properties, glued line thickness, moisture, and geometry. Worldwide, research inquiries and the testing of these joints, focusing on various influences and their combinations affecting their bearing capacity, are already in progress. For example, authors in [9] focus on the mechanical behavior of these joints. 
Other works are mainly devoted to the carrying capacity of adhesives in combination with various aspects [10-12] and the thickness of the glued lines [13].

When the maximum load-carrying capacity of these joints is reached, there is a sudden failure of the joint by brittle fracture. Sudden failure without large deformation is very dangerous and affects the reliability of structures. Therefore, we decided to add another fastener with plastic deformation properties to a brittle bonded joint in order to ensure greater ductility and thereby increase its safety, even at the cost of large deformations. The occurrence of these deformations highlights the overloading of the joint and allows for corrective action. This is the reason we tested both glued and screw joints themselves as well as their combination.

\section{Materials and Methods}

\subsection{Laboratory Testing}

To analyze the load-bearing capacity of a longitudinal joint subjected to simple flexural stress, destructive laboratory testing was performed on sample joints designed with three basic types of splices in a central beam: by gluing, by gluing in combination with mechanical fasteners, and using only mechanical fasteners. Two material variants of splices were selected: from mature and laminated veneer lumber. In total, six test sets were created for two material variants of splices in combination with three methods of their fastening. Each test set consisted of five samples. For the testing, samples were assembled consisting of a central beam with dimensions $110 \times 180 \times 1220 \mathrm{~mm}$ and made of solid timber with the use of laminate veneer lumber splices and splices made of solid timber (see Figure 1).
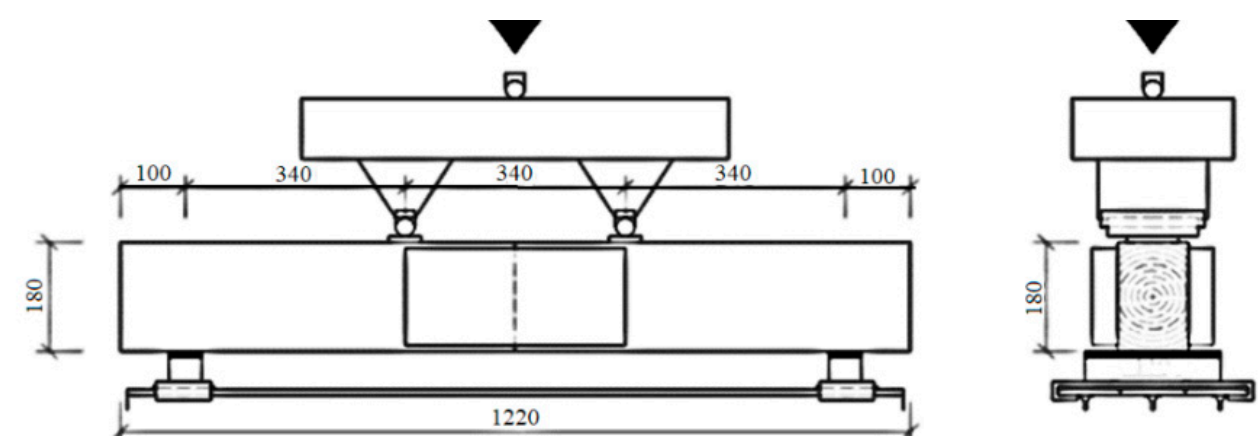

Figure 1. Laboratory testing scheme.

The central beam and solid timber splices were made of solid spruce (Picea abies), which has a strength class of $\mathrm{C} 24$ and average density of $370 \mathrm{~kg} \mathrm{~m}^{-3}$. Laminated veneer lumber (LVL) splices were made of the $\mathrm{R}$ type softwood veneers (spruce/pine) with average density of $510 \mathrm{~kg} \mathrm{~m}^{-3}$.

Two-component epoxy adhesive was used for structural gluing, which was applied in a $2 \mathrm{~mm}$ thick layer on the entire contact surface between the splice and central element.

The test samples were conditioned prior to destructive testing at a standard ambient temperature of $20 \pm 2{ }^{\circ} \mathrm{C}$ and relative humidity of $65 \pm 5 \%$. To determine the moisture in the test samples, a moisture detector was used. The average moisture content of tested elements was $10.2 \%$.

Countersunk self-tapping screws were used as the mechanical fasteners: $\varnothing 8 / 80$ for joints with splices with laminated veneer lumber and $\varnothing 8 / 100$ for joints with splices made of solid timber. Screws were made of carbon steel with white galvanic zinc coating and had a yield strength $f_{y k}=1000 \mathrm{~N} \mathrm{~mm}^{-2}$. For the joining of each splice, eight screws were used (see Figure 2). 


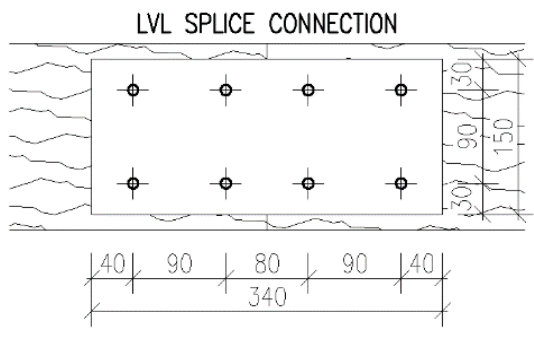

(a)

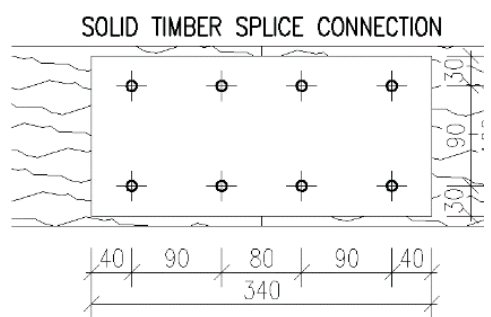

(b)

Figure 2. Layout char of screws. (a) Laminated veneer lumber (LVL) splice; (b) Solid timber splice.

Testing proceeded on a hydraulic pressure machine at the laboratories of the Faculty of Civil Engineering, VSB-TU Ostrava, and force was increased gradually. The sample was loaded with vertical force applied in thirds of the span. An optimal force rate was chosen for the press. Failure among all tested samples appeared in a time boundary of $300 \pm 120 \mathrm{~s}$ which corresponds to the interval of laboratory tests for short-time strength according to the current European standards for timber structure capacity $[14,15]$.

During testing, the force (maximum joint force) was recorded for each test sample (accuracy of $0.01 \mathrm{kN}$ ), and the corresponding deformation of the joint was measured in the supports and in the middle of the span at half the height of the cross-section of the test sample (accuracy of $0.01 \mathrm{~mm}$ ).

\subsection{Calculation According to Standards}

\subsubsection{Glued Joints}

According to previous laboratory tests and numerical calculations, this type of joint has two basic types of failure: failure along the glue line $\left(R_{b c 1}\right)$ or failure of splice veneers (LVL or solid timber). Failure along the glue line is calculated with two variants: uniform $\left(R_{b c 2}\right)$ and unequal $\left(R_{b c 3}\right)$ distribution of shear stress.

Calculation of the maximum joint force $R_{b c}$ is based on the moment transferred by the glued joint for both central elements as well as the designed load-carrying capacity of the joint (Figure 3 ).

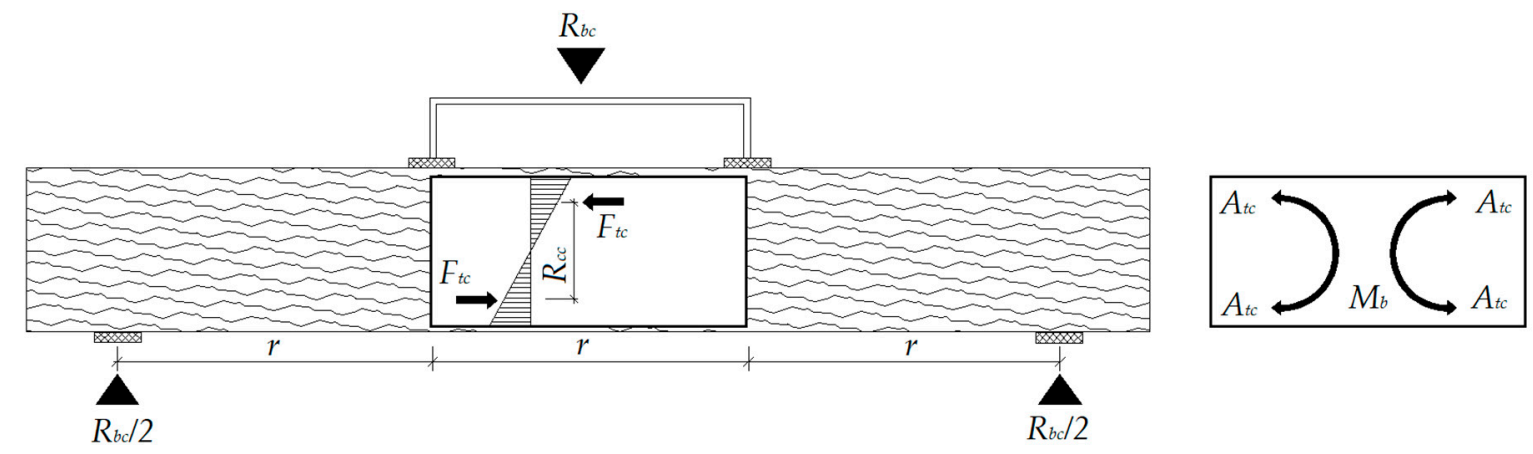

Figure 3. Maximum joint force-glued joint.

The maximum joint force $R_{b c}$ is determined from the following expression:

$$
R_{b c}=\frac{2 M_{b}}{r}[\mathrm{kN}]
$$

where $M_{b}$ is the moment transferred by the glued joint, and $r$ is the lever arm of the test sample.

The moment transferred by the glued joint is determined from the following expression:

$$
M_{b}=F_{t c} \times 2 \times R_{c c}[\mathrm{kNm}]
$$


where $F_{t c}$ is the designed load-carrying capacity of the joint determined from expression (3) for shear strength of the splice material and (4) for strength of the glue line. $R_{c c}$ is the lever arm of forces acting on the joint.

Rgarding the load-carrying capacity of the joint, the shear strength of the splice material is determined as follows:

$$
F_{t c}=\frac{f_{v, k} \times k_{\bmod } \times A_{t c}}{2 \times \gamma_{M}}[\mathrm{kN}]
$$

where $A_{t c}$ is the active glued area of the joint, and $f_{v, k}$ is the shear strength of the splice material.

Regarding the load-carrying capacity of the joint, the glue line strength is determined as

$$
F_{t c}=\frac{f_{k} \times k_{\text {mod }} \times A_{t c}}{2 \times \gamma_{M}}[\mathrm{kN}]
$$

where $A_{t c}$ is the active glued area of the joint, and $f_{k}$ is the strength of the glued surface for uniform and unequal distribution of shear stress.

\subsubsection{Screw Joints}

The maximum joint force $R_{b c 4}$ (see Figure 4 ) is based on the load-carrying capacity of the single shear fastener and is determined from the following expression:

$$
R_{b c}=\frac{2 M_{b}}{r}[\mathrm{kN}]
$$

where $M_{b}$ is the moment transferred by the glued joint, and $r$ is the lever arm of the test sample.

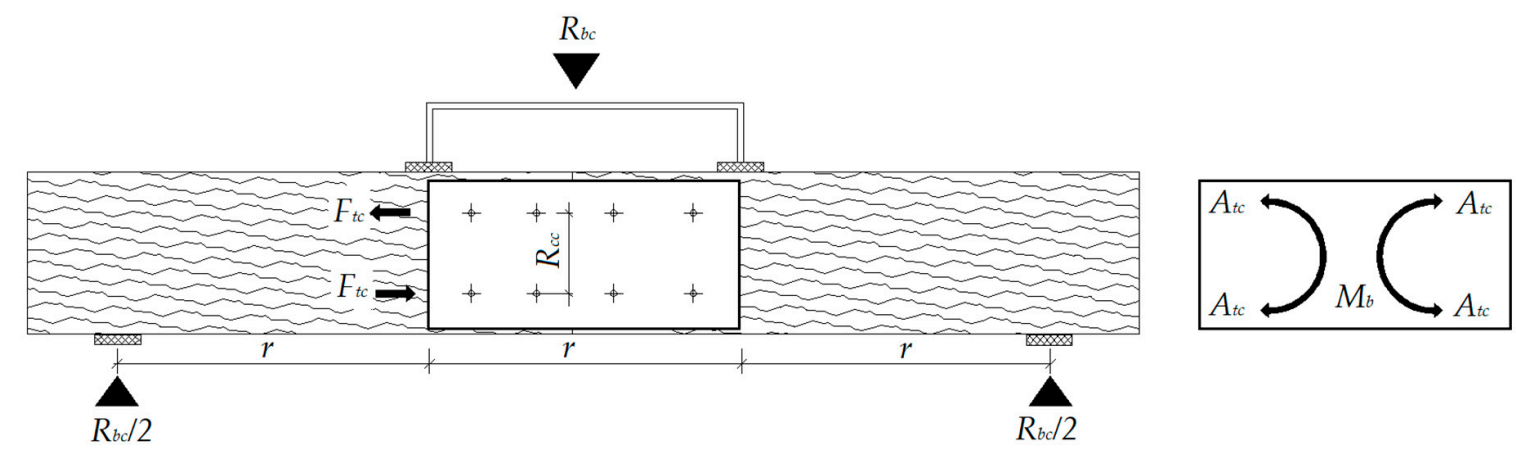

Figure 4. Maximum joint force-screw joint.

The moment transferred by the joint onto the beams is determined using the following expression:

$$
M_{b}=F_{v, R d} \times 2 \times 2 \times R_{c c}[\mathrm{kNm}]
$$

where $F_{v, R d}$ is the designed load-carrying capacity for the fastener per shear plane, and $R_{c c}$ is the lever arm of forces acting on the joint.

Design load-carrying capacity for fastener per shear $F_{v, R d}$ is determined according to expressions given in [14].

\subsubsection{Combination of Gluing and Screws}

In the applicable standards, the calculation of load-carrying capacity for combined joints with glued and mechanical fasteners is not described; thus, the maximum strength is not designated for these joints. Essentially, joints of varying rigidity should not be combined, and if they are, they should have at least a similar load-carrying capacity. 


\section{Results}

\subsection{Laboratory Testing}

Based on laboratory test results, statistical variables were determined for each set of samples for maximum joint force (failure force) and vertical deformation of the joint.

\subsubsection{Glued Joints}

The mean value of the maximum force acting on the joint with glued LVL splices was $R_{b c}=28.86 \mathrm{kN}$, and with solid timber splices it was $R_{b c}=30.80 \mathrm{kN}$. The mean value of vertical deformation at maximal force with glued LVL splices was $8.38 \mathrm{~mm}$, and with solid timber splices it was $9.03 \mathrm{~mm}$ (Table 1).

Table 1. Glued joints-laboratory results.

\begin{tabular}{cccc}
\hline & & Force [kN] & Vertical Deformation [mm] \\
\hline \multirow{3}{*}{ LVL } & Mean & 28.86 & 8.38 \\
& SD & 4.24 & 0.39 \\
& COV & 0.15 & 0.05 \\
\hline \multirow{3}{*}{ Solid timber } & Mean & 30.80 & 9.03 \\
& SD & 6.72 & 1.24 \\
& COV & 0.22 & 0.14 \\
\hline
\end{tabular}

Figure 5 shows that the deformation curves of glued joints with both types of splices were partially linear; only in the final phase of loading did the joints start to show plastic deformation. When the maximum load-carrying capacity of these joints was reached, there was a sudden failure of the joint by brittle fracture.

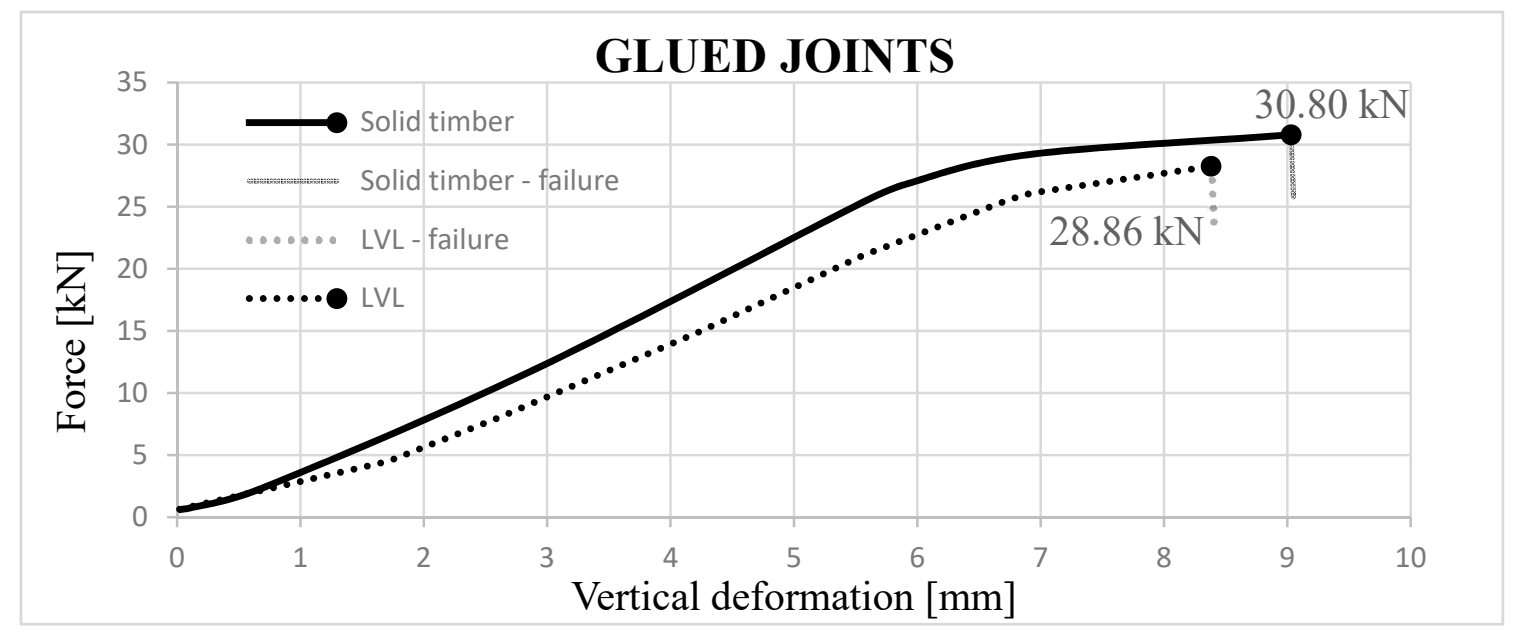

Figure 5. Glued joints-deformation curves.

Joints with LVL splices suffered primarily from shear failure of the first or second veneer from the glue line (Figure 6). 


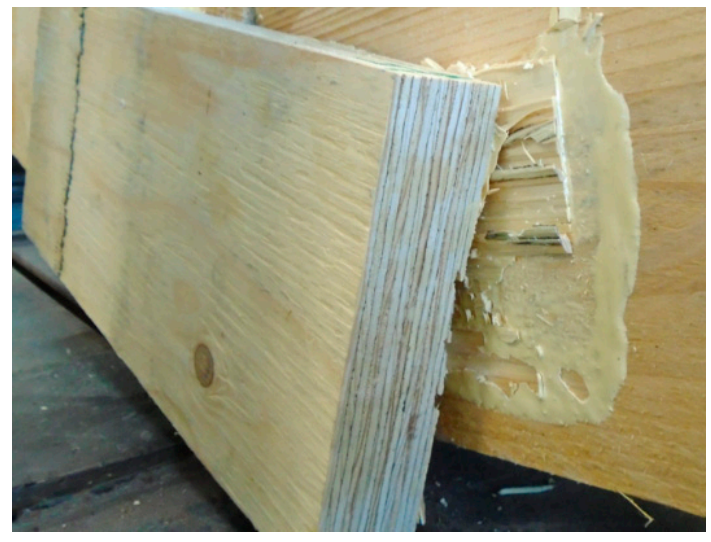

(a)

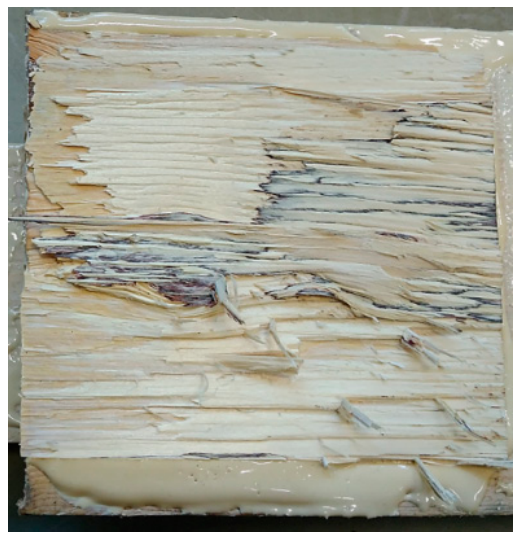

(b)

Figure 6. Glued joints with LVL splice. (a) Typical failure; (b) Detailed image.

Joints with solid timber splices primarily suffered splice failure in combination with shear and tension perpendicular to the grain. This failure was characterized by cracks forming in the area of the glue line. The joint predominately failed due to tension perpendicular to the grain. (Figure 7).
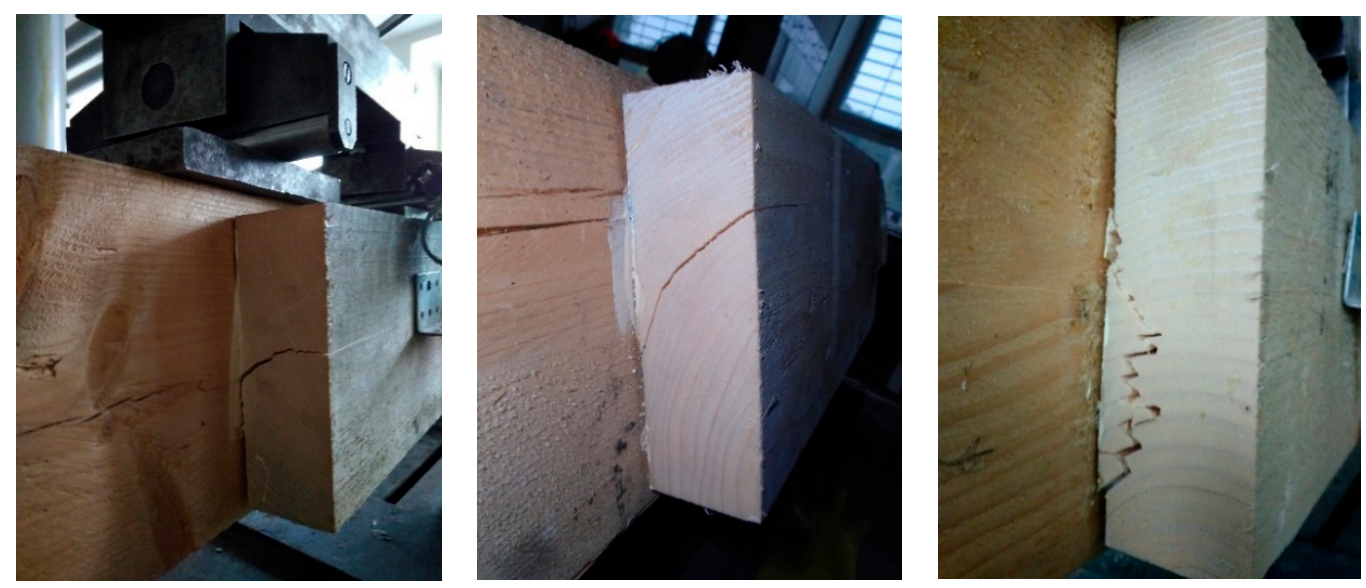

Figure 7. Glued joints with solid timber splice: typical failure of solid timber splice.

\subsubsection{Screw Joints}

The mean value of the maximum joint force for the set of samples with screws and LVL splices was $R_{b c}=16.32 \mathrm{kN}$, and for solid timber splices it was $R_{b c}=18.98 \mathrm{kN}$. The mean value of vertical deformation at the maximal force with screwed LVL splices was $53.61 \mathrm{~mm}$, and with solid timber splices it was $54.12 \mathrm{~mm}$ (Table 2).

Table 2. Screw joints-laboratory results.

\begin{tabular}{cccc}
\hline & & Force [kN] & Vertical Deformation [mm] \\
\hline \multirow{4}{*}{ LVL } & Mean & 16.32 & 53.61 \\
& SD & 1.94 & 12.78 \\
& COV & 0.12 & 0.25 \\
\hline \multirow{3}{*}{ Solid timber } & Mean & 18.98 & 54.12 \\
& SD & 1.73 & 13.27 \\
& COV & 0.09 & 0.25 \\
\hline
\end{tabular}


Figure 8 shows the deformation curves of this type of joint were partially linear, and then the joint had ductile behavior. Ductility is typical for mechanical fasteners, especially for small-diameter fasteners that can bend. When the maximum load-carrying capacity of this joint was reached, there was a sudden failure of the joint; however, due to the use of mechanical fasteners (i.e., screws), total failure was postponed. The joint displayed ductile behavior, and its load-carrying capacity was limited by the mechanical joint. In the final phase, excessive bending of the outer screws, closer to the center of the joint, simultaneously occurred as the splice split perpendicular to its longitudinal axis.

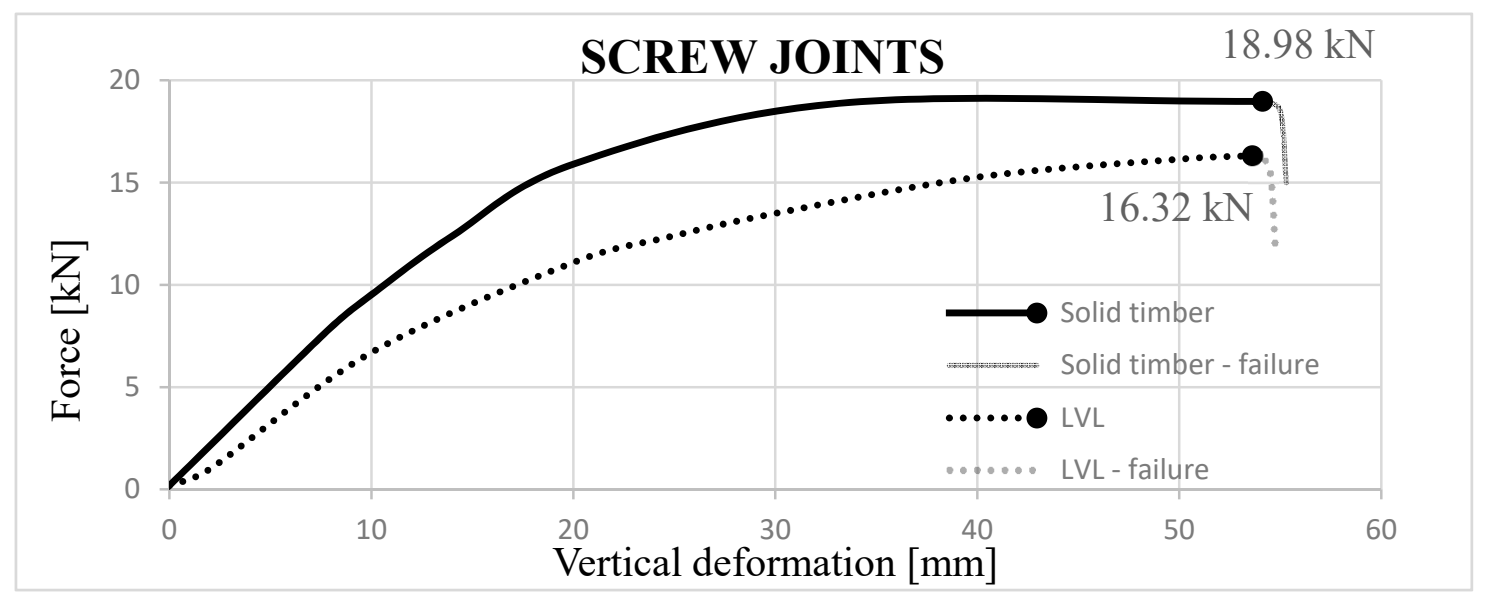

Figure 8. Screw joints-deformation curves.

The most common type of joint failure with screwed LVL splices was splitting perpendicular to veneers at the screw level (see Figure 9).
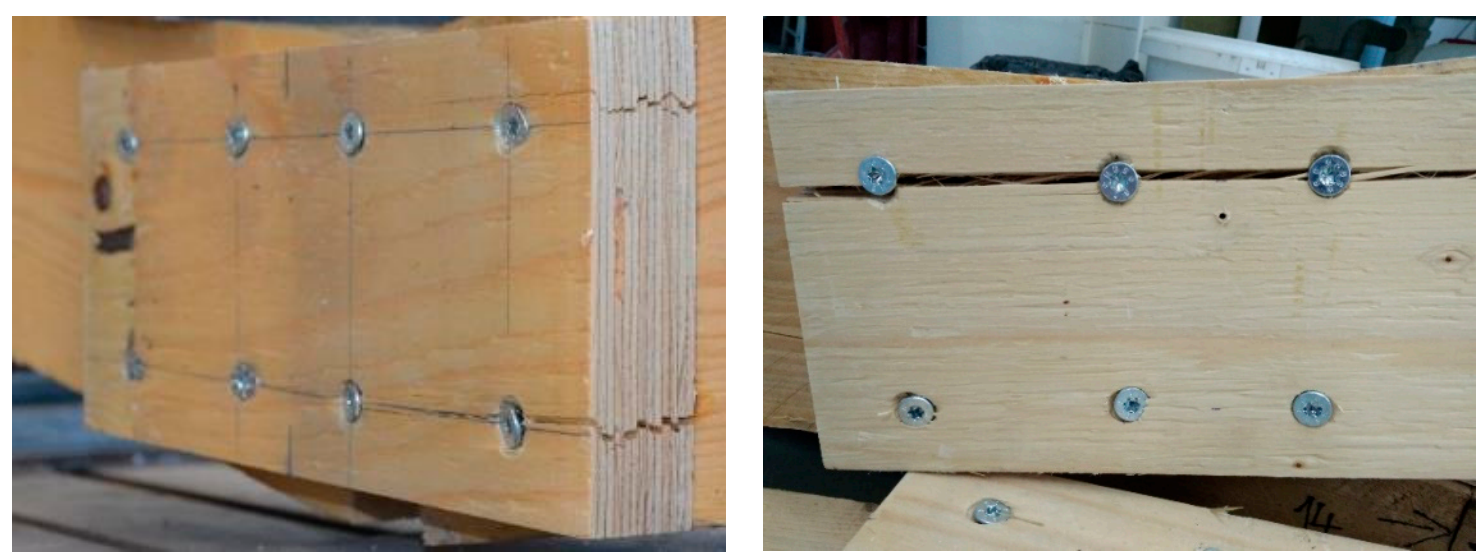

Figure 9. Screw joints with LVL splice: typical failures.

Failure for screwed solid timber splices was the same as that with LVL splices: splitting was perpendicular to veneers at the screw level (see Figure 10). 

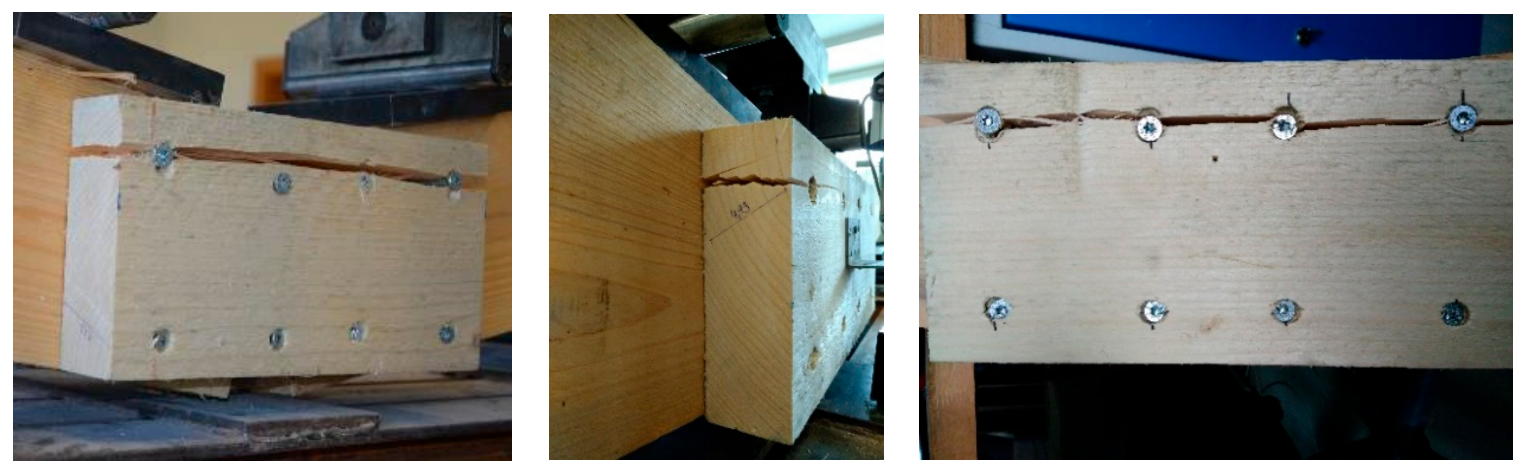

Figure 10. Screw joints with solid timber splice: typical failure of solid timber splice.

\subsubsection{Combination of Gluing and Screws}

The mean value of the maximum joint force for the set of samples with a combination of gluing and screws was $R_{b c}=30.40 \mathrm{kN}$ for LVL splices, and for solid timber splices it was $R_{b c}=35.16 \mathrm{kN}$.

The mean value of vertical deformation at the maximal force was $7.68 \mathrm{~mm}$ for LVL splices, and for solid timber splices it was $10.90 \mathrm{~mm}$ (Table 3).

Table 3. Combination of gluing and screw joints-laboratory results.

\begin{tabular}{cccc}
\hline & & Force [kN] & Vertical Deformation [mm] \\
\hline \multirow{4}{*}{ LVL } & Mean & 30.04 & 37.78 \\
& SD & 5.21 & 6.22 \\
& COV & 0.18 & 0.17 \\
\hline \multirow{3}{*}{ Solid timber } & Mean & 35.16 & 34.53 \\
& SD & 2.67 & 9.19 \\
& COV & 0.08 & 0.28 \\
\hline
\end{tabular}

Vertical deformation increased even after reaching the maximal joint force. The mean value of the maximal vertical deformation was $37.78 \mathrm{~mm}$ for LVL splices, and with solid timber splices it was $34.56 \mathrm{~mm}$ (Figure 11).

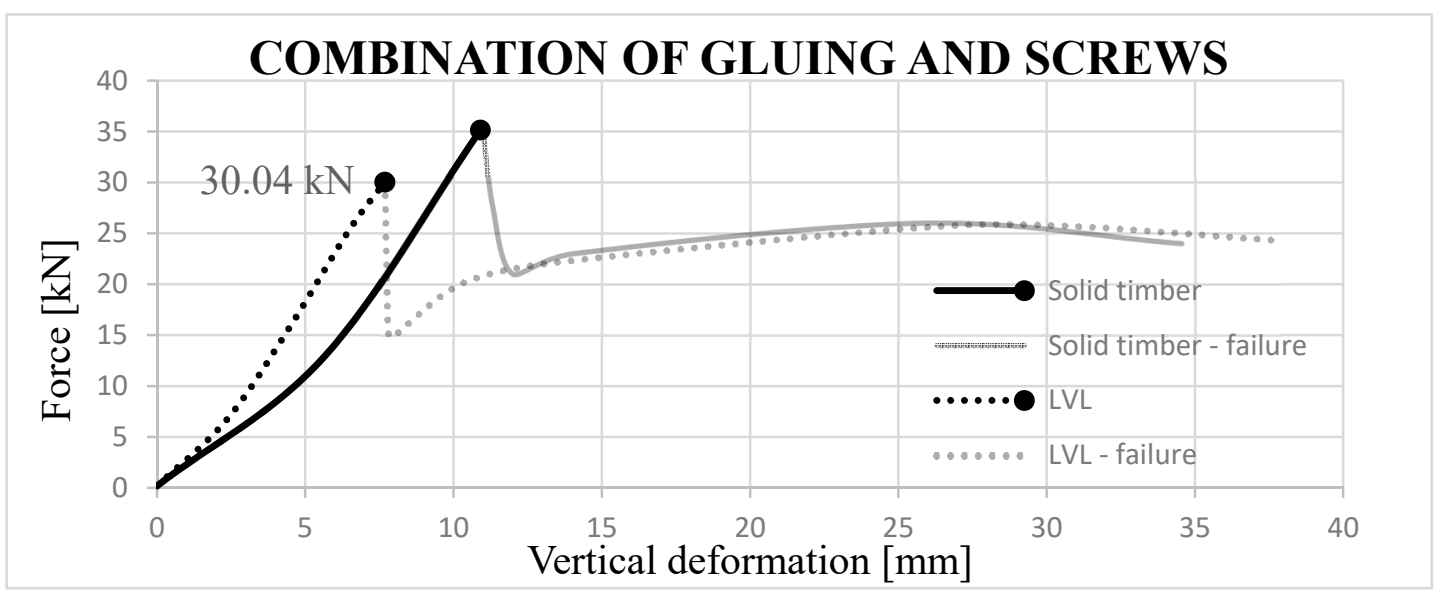

Figure 11. Combination of gluing and screw joints—deformation curves.

Figure 11 shows that the deformation curves of this type of joint were partially linear. When the maximum load-bearing capacity of this joint was reached, there was a sudden failure of the joint by brittle fracture, but total failure was delayed as a result of using mechanical fasteners (i.e., screws). 
The joint displayed ductile behavior, and its load-bearing capacity was limited by the mechanical joint. After the mechanical joint's maximum load-carrying capacity was reached, the splice was split by tensile force perpendicular to the fibers (brittle behavior of timber).

The first or second veneer primarily suffered shear failure in this type of joint with LVL splicing. Thereafter, splitting of the upper pressed and bottom tensional parts of the splice occurred in the plane of screws (Figure 12).
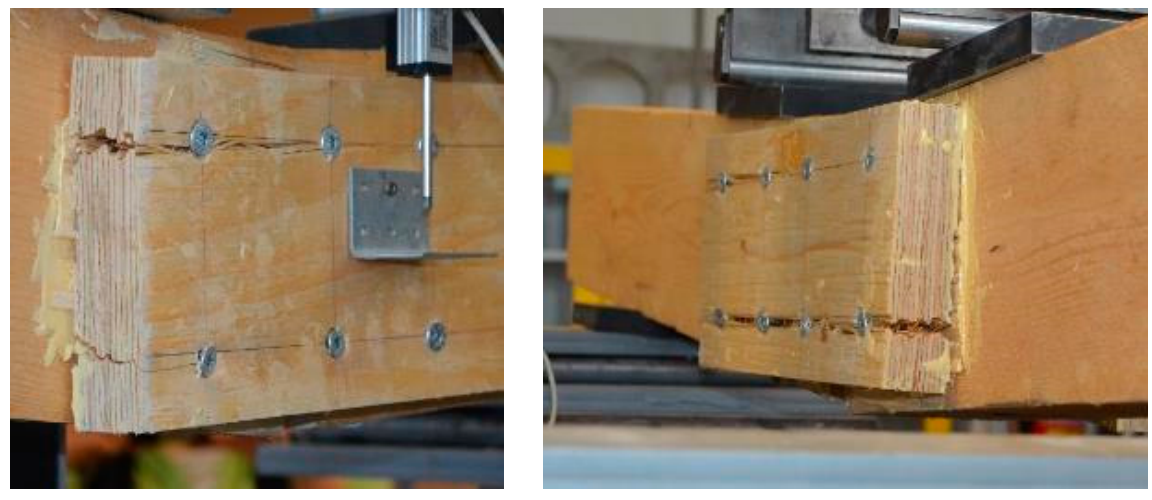

Figure 12. Combination of gluing and screws with LVL splice: typical failures of LVL splice.

This type of joint with solid timber splices primarily suffered splitting in the upper pressed part of the splice in the plane of screws, while it simultaneously developed a crack from the middle element (beam) parallel or perpendicular to the annual rings, which was the same as for solid timber splices (Figure 13).
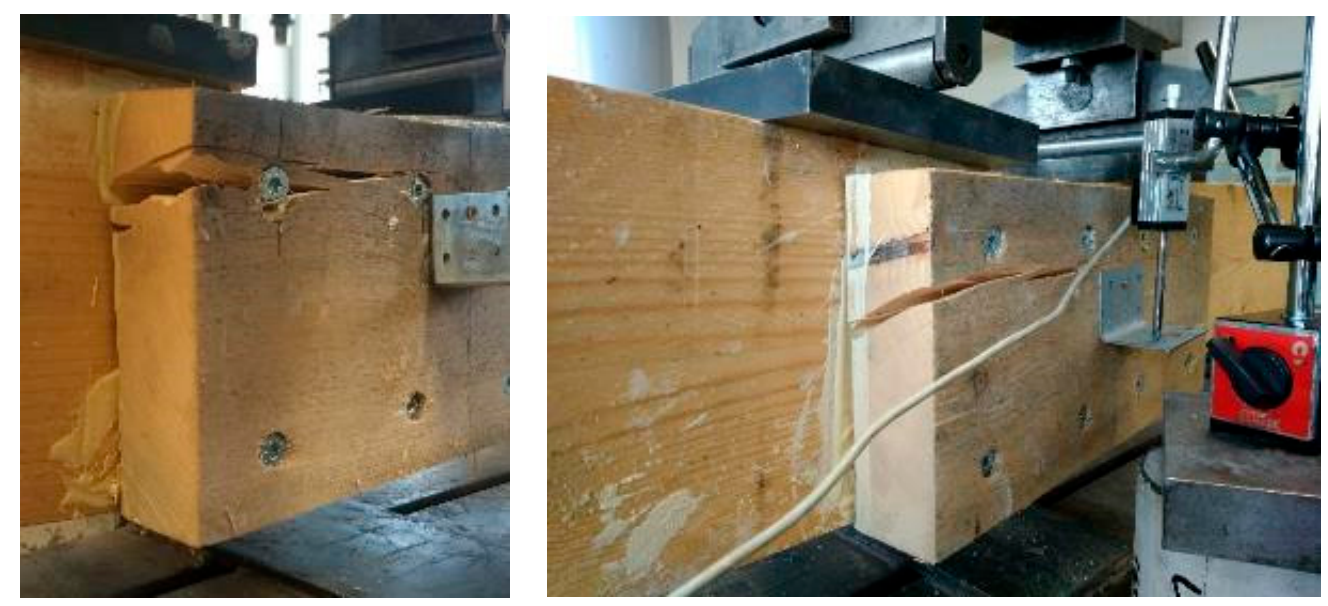

Figure 13. Combination of gluing and screws with solid timber splice: typical failures of solid timber splice.

\subsection{Calculation According to Standards}

\subsubsection{Glued Joints}

The maximum force of the glued joint $R_{b c}$ is designated using Formulas (1) to (4), as described in Section 2.2.1.

The resulting values for the maximum glued joint force $\left(R_{b c 1}\right)$ at the maximum load-carrying capacity of the splice in shear for LVL and solid timber are shown in Table 4. 
Table 4. Load-carrying capacity of splices in shear.

\begin{tabular}{cccc}
\hline & & Quantity & Unit \\
\hline \multirow{4}{*}{ LVL } & $F_{t c 1}$ & 20.30 & $\mathrm{kN}$ \\
& $M_{b d 1}$ & 4.06 & $\mathrm{kNm}$ \\
& $R_{b c 1}$ & 23.88 & $\mathrm{kN}$ \\
\hline \multirow{3}{*}{ Solid timber } & $F_{t c 1}$ & 18.83 & $\mathrm{kN}$ \\
& $M_{b d 1}$ & 4.02 & $\mathrm{kNm}$ \\
& $R_{b c 1}$ & 23.63 & $\mathrm{kN}$ \\
\hline
\end{tabular}

The resulting values for the maximum glued force at the maximum load-carrying capacity of the glue line for LVL and solid timber are shown in Table 5 for a uniform distribution of shear stress $\left(R_{b c 2}\right)$ and in Table 6 for an unequal distribution of shear stress $\left(R_{b c 3}\right)$.

Table 5. Load-carrying capacity of the glue-line: uniform distribution of shear.

\begin{tabular}{cccc}
\hline & & Quantity & Unit \\
\hline \multirow{4}{*}{ LVL } & $F_{t c 1}$ & 6.62 & $\mathrm{kN}$ \\
& $M_{b d 1}$ & 1.32 & $\mathrm{kNm}$ \\
& $R_{b c 1}$ & 7.79 & $\mathrm{kN}$ \\
\hline \multirow{4}{*}{ Solid timber } & $F_{t c 1}$ & 7.06 & $\mathrm{kN}$ \\
& $M_{b d 1}$ & 1.51 & $\mathrm{kNm}$ \\
& $R_{b c 1}$ & 8.86 & $\mathrm{kN}$ \\
\hline
\end{tabular}

Table 6. Load-carrying capacity of the glue-line: unequal distribution of shear.

\begin{tabular}{cccc}
\hline & & Quantity & Unit \\
\hline \multirow{4}{*}{ LVL } & $F_{t c 1}$ & 3.31 & $\mathrm{kN}$ \\
& $M_{b d 1}$ & 0.66 & $\mathrm{kNm}$ \\
& $R_{b c 1}$ & 3.89 & $\mathrm{kN}$ \\
\hline \multirow{4}{*}{ Solid timber } & $F_{t c 1}$ & 3.53 & $\mathrm{kN}$ \\
& $M_{b d 1}$ & 0.75 & $\mathrm{kNm}$ \\
& $R_{b c 1}$ & 4.43 & $\mathrm{kN}$ \\
\hline
\end{tabular}

\subsubsection{Screw Joints}

The maximum joint force for screwed joint $R_{b c 4}$ (Table 7) is designated using formulas (5) and (6) and Johansen formulas according to [14] for determining the load-carrying capacity of one fastener per shear plane.

Table 7. Load-carrying capacity of screwed joints.

\begin{tabular}{cccc}
\hline & & Quantity & Unit \\
\hline \multirow{4}{*}{ LVL } & $F_{t c 1}$ & 3.73 & $\mathrm{kN}$ \\
& $M_{b d 1}$ & 1.34 & $\mathrm{kNm}$ \\
& $R_{b c 1}$ & 7.89 & $\mathrm{kN}$ \\
\hline \multirow{3}{*}{ Solid timber } & $F_{t c 1}$ & 4.10 & $\mathrm{kN}$ \\
& $M_{b d 1}$ & 1.64 & $\mathrm{kNm}$ \\
& $R_{b c 1}$ & 9.64 & $\mathrm{kN}$ \\
\hline
\end{tabular}

\section{Summary}

Figure 14 shows a comparison of the load-carrying capacity of glued joints with LVL splices determined using laboratory tests and calculations according to European standards. Results are 
displayed as deformation curves, with a maximum joint force of $28.26 \mathrm{kN}$. The load-carrying capacity of this joint type, determined using calculations according to valid standards, had three values for LVL splices: the load-carrying capacity of splices in shear was $R_{b c 1}=23.88 \mathrm{kN}$, of the glue-line with uniform distribution of shear was $R_{b c 2}=7.79 \mathrm{kN}$, and of the glue-line with unequal distribution of shear was $R_{b c 3}=3.89 \mathrm{kN}$.

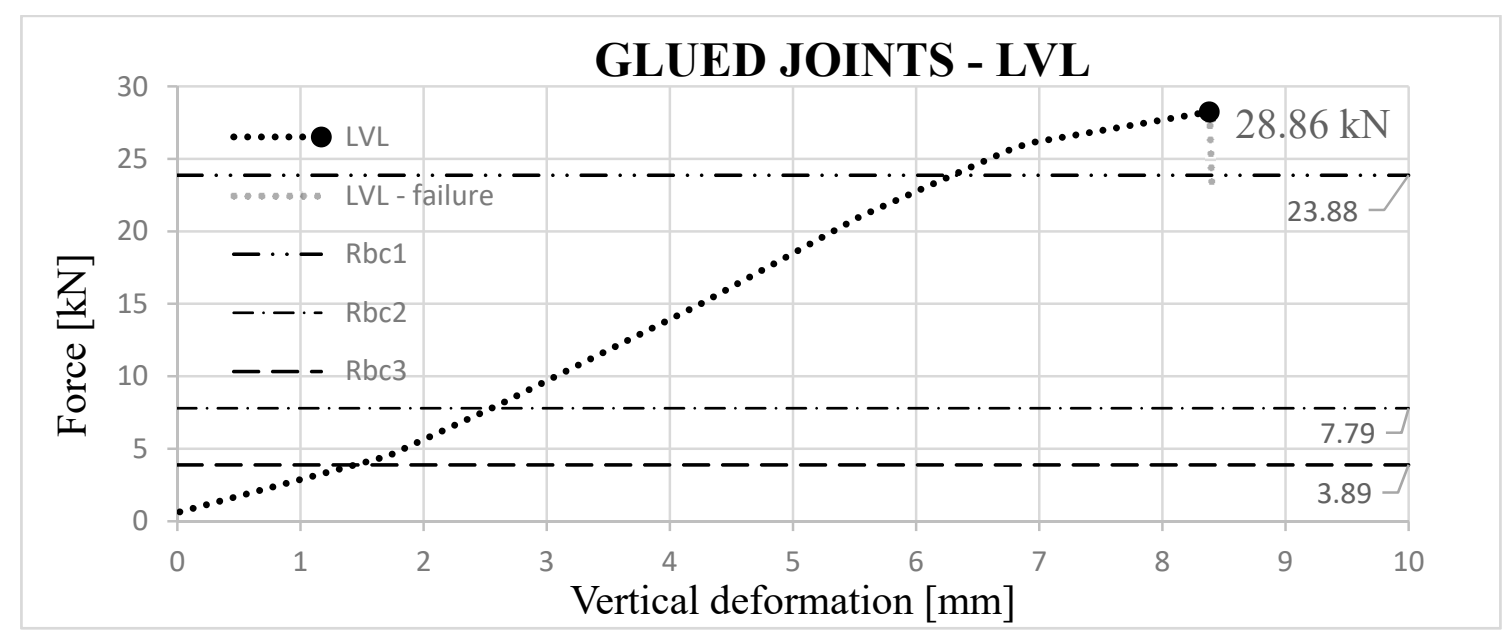

Figure 14. Joints with LVL splices—comparison of laboratory and calculation results.

Figure 15 compares the load-carrying capacity of glued joints with solid timber splices determined using laboratory tests and calculations according to European standards. Results are displayed as deformation curves, with a maximum joint force of $30.80 \mathrm{kN}$. The load-carrying capacity of this joint type, determined using calculations according to valid standards, had three values for solid timber splices: the load-carrying capacity of splices in shear was $R_{b c 1}=23.63 \mathrm{kN}$, of the glue-line with uniform distribution of shear was $R_{b c 2}=8.86 \mathrm{kN}$, and of the glue-line with unequal distribution of shear was $R_{b c 3}=4.43 \mathrm{kN}$.

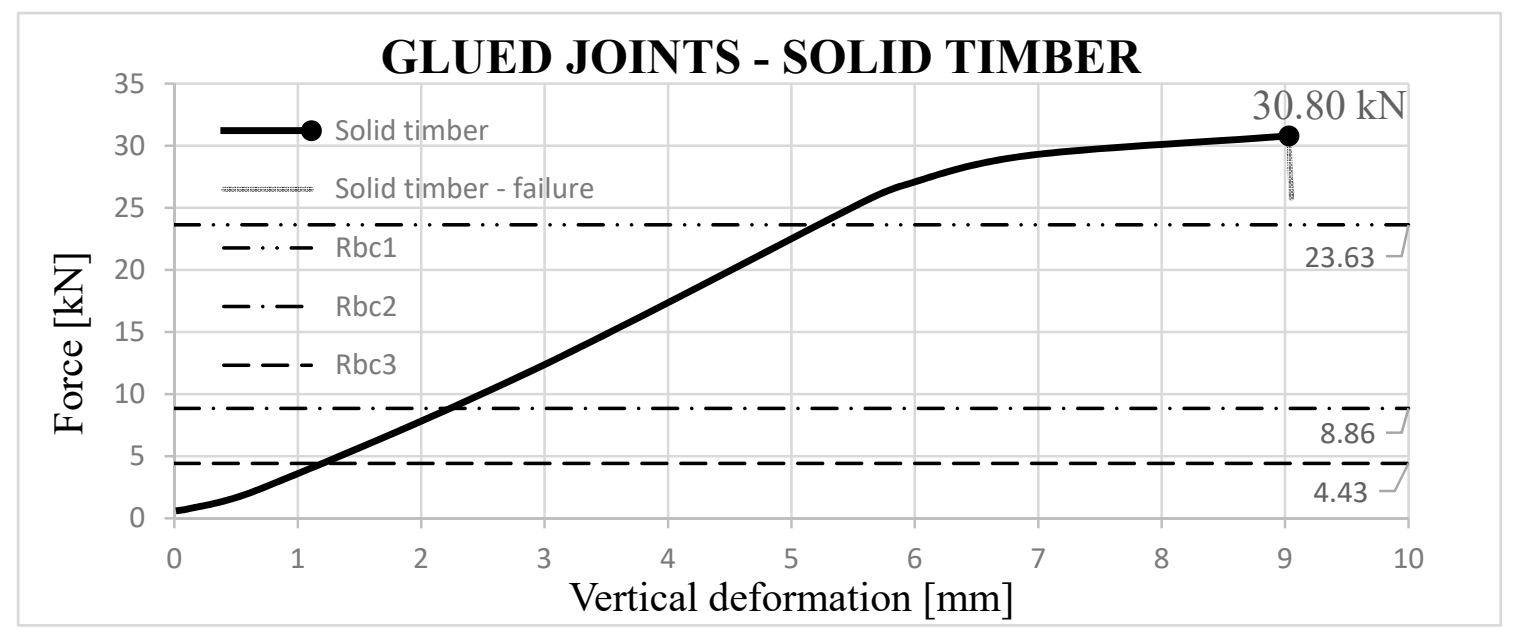

Figure 15. Screw joints with solid timber splices—comparison of laboratory and calculation results.

Figure 16 compares the load-carrying capacity of screwed joints with LVL splices determined using laboratory tests and calculations according to European standards. Results are displayed as deformation curves, with maximum joint force of $16.32 \mathrm{kN}$. The load-carrying capacity of this joint type was $R_{b c 4}=7.89 \mathrm{kN}$, calculated according to valid standards. 


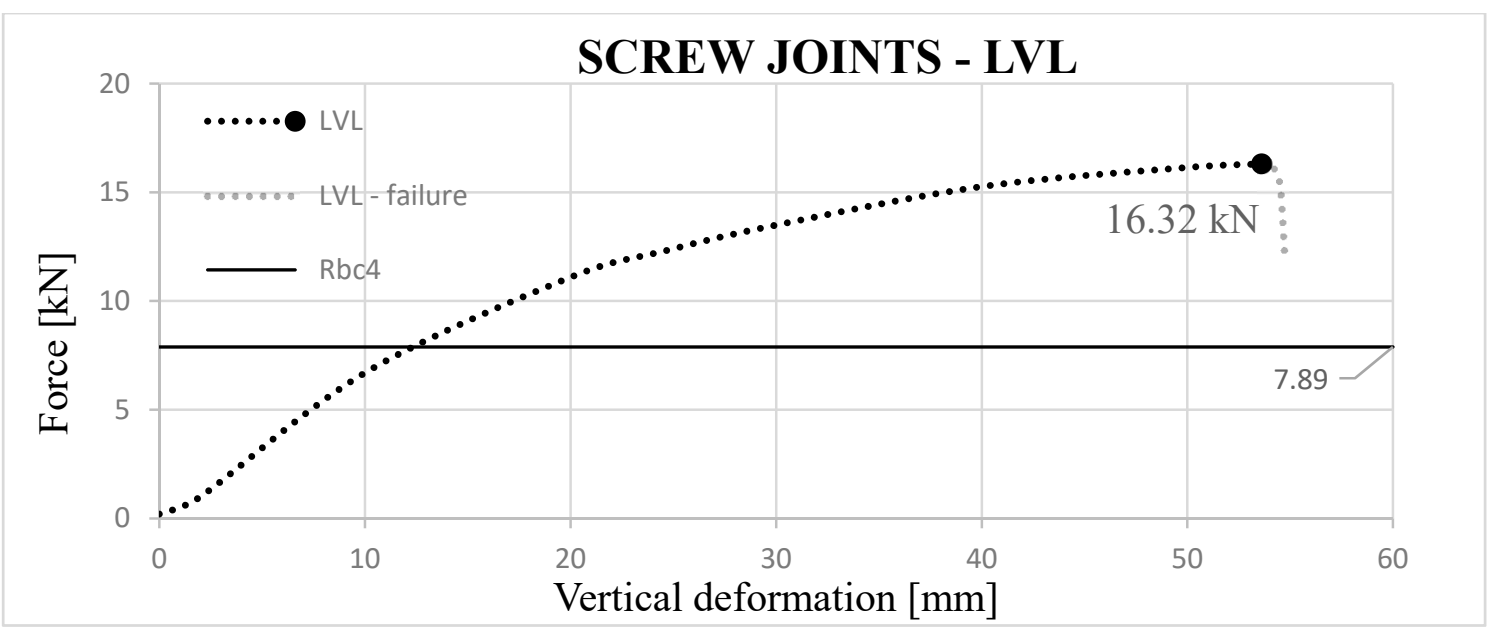

Figure 16. Screw joints with LVL splices—comparison of laboratory and calculation results.

Figure 17 compares the load-carrying capacity of screwed joints with solid timber splices determined using laboratory tests and calculations according to standards. Results are displayed as deformation curves, with maximum joint force of $118.98 \mathrm{kN}$. The load-carrying capacity of this joint type was $R_{b c 4}=9.64 \mathrm{kN}$, calculated according to valid standards.

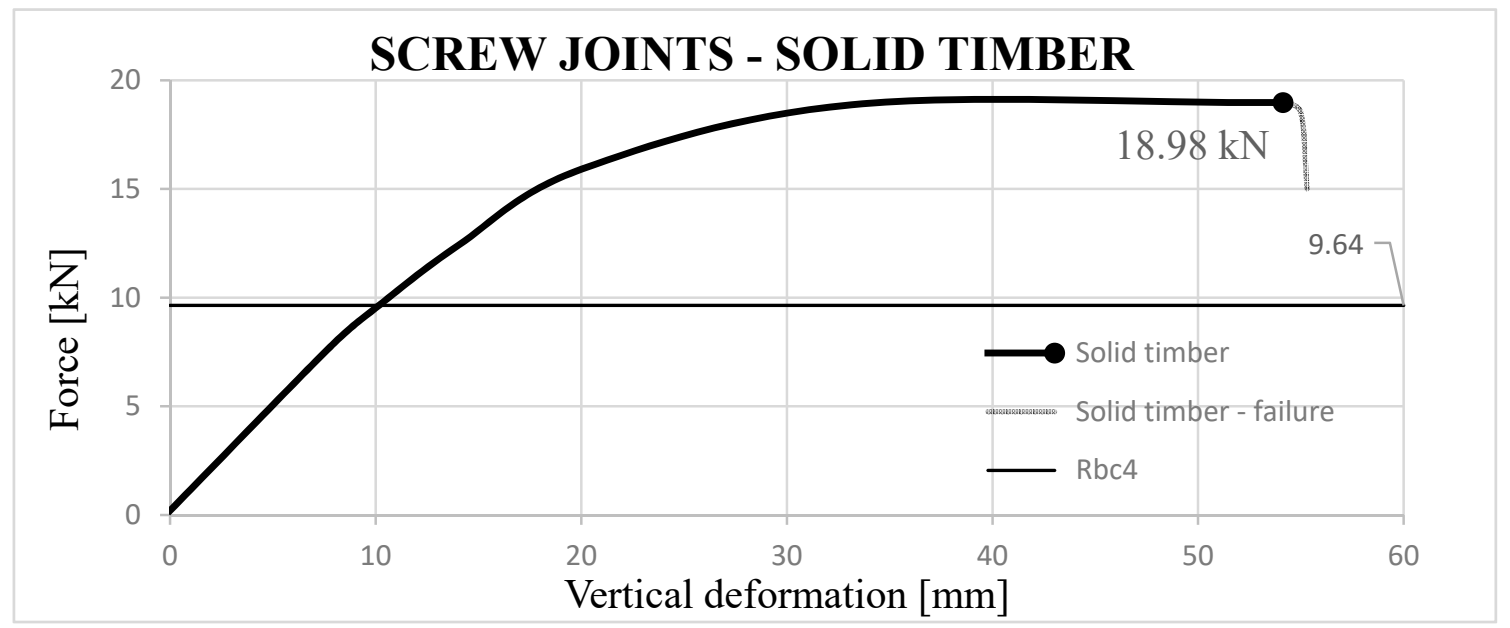

Figure 17. Screw joints with solid timber splices—comparison of laboratory and calculation results.

Figure 18 shows the deformation curves of all six tested sample sets-LVL and solid timber splices in combination with three connection types: gluing, screws, and combination.

Figure 18 shows the deformation curves of glued joints were partially linear. When the maximum load-carrying capacity of these joints was reached, there was a sudden failure of the joint by brittle fracture.

Deformation curves of screwed joints were partially linear, and then the joint had a ductile behavior. Ductility is typical for mechanical fasteners, especially for small-diameter fasteners that can bend. When the maximum load-carrying capacity of this joint was reached, there was a sudden failure of the joint; however, due to the mechanical fasteners (i.e., screws), total failure was postponed.

Figure 11 shows the deformation curves of this joint type were partially linear. When the maximum load-bearing capacity of this joint was reached, there was a sudden failure of the joint by brittle fracture, but total failure was delayed as a result of using screws. The joint displayed ductile behavior, and its load-bearing capacity was limited by the mechanical joint. 


\section{COMPARISON OF ALL DEFORMATION CURVES}

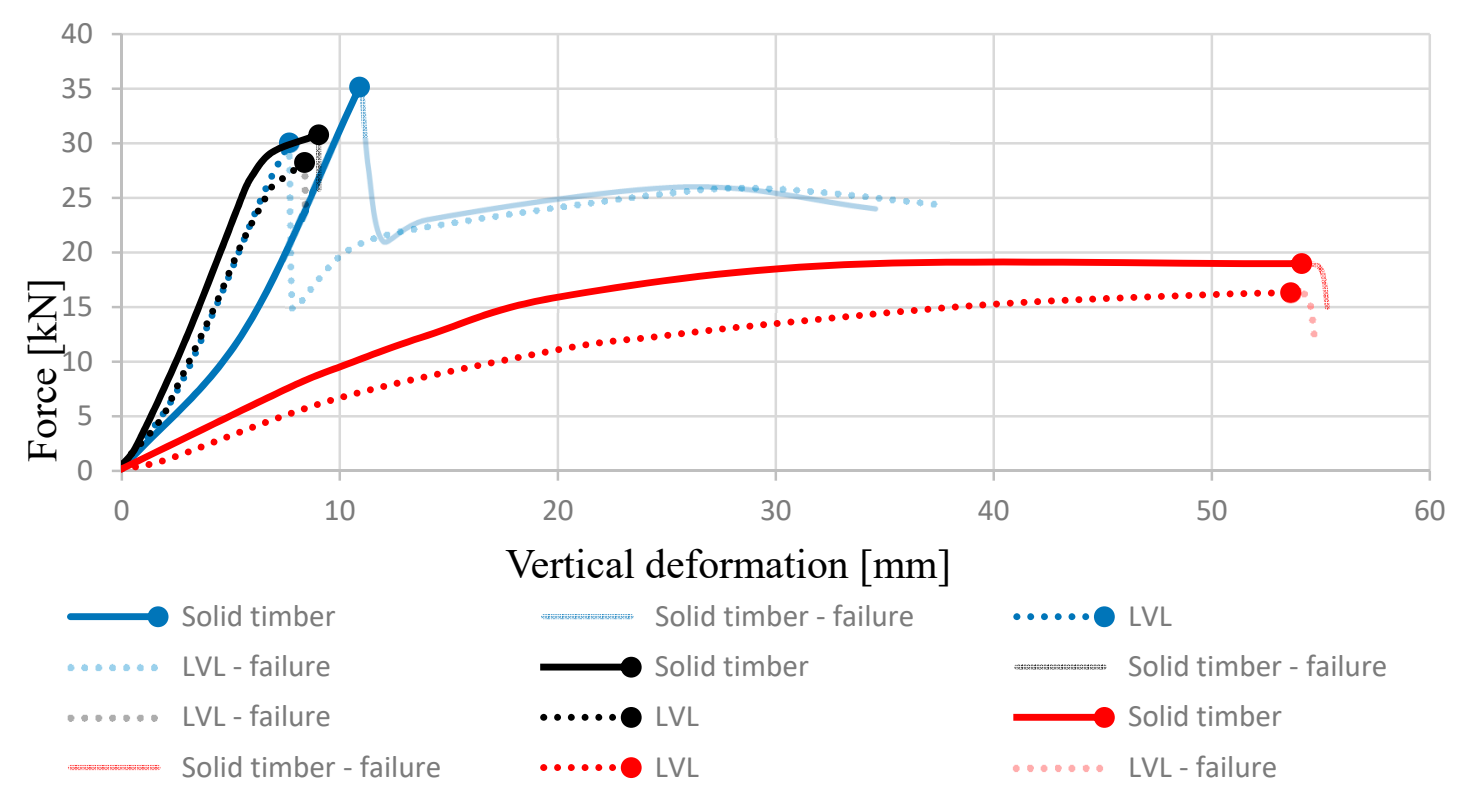

Figure 18. Screw joints with solid timber splices—comparison of laboratory and calculation results.

\section{Discussion}

Based on the results from our laboratory measurements, one can state that glued and combined joints displayed a higher values of potential load acting on the joint compared to that of joints with only mechanical fasteners. Glued joints alone (i.e., not combined with screws) suffered sudden failure (brittle fracture) when the maximum load was reached.

For this reason, combined joints appear to be beneficial and include both the rigidity and strength of glued joints as well as the good properties of mechanical fasteners due to their plastic behavior (ductility) when the joint's load-bearing capacity is reached.

Ductility is typical for mechanical fasteners, especially for small-diameter fasteners that can bend. Their use is suitable in building structures because, before failure, the joints indicate impending failure by their increased deformations.

\section{Conclusions}

Based on our calculations and laboratory tests, information can be acquired regarding glued, screw, as well as combined connections of beams using double-sided slices made of wood and wood-based materials stressed by pure bending without the influence of shear force. Glued splices had higher rigidity in comparison to screwed. Brittle failure of the joint occurred by shear force in a layer of wood; in the case of LVL splices, failure occurred in the veneer closest to the glued layer (this is the dominant combined failure seen by rolling shear force and tension parallel to the grain). Thus, increasing the splice thickness does not necessarily lead to increased rigidity or bearing capacity of the joint. The load-bearing capacity of the joint is, therefore, proportional to the dimensions of splices, the quality of the adhesive and actual application of the adhesive, surface coverage, and creation of the active surface (epoxy two-component resin).

It is advisable to use adhesives that do not show brittle failure and do not form a rigid boundary layer, which could cause local extremes in stress due to different wood behaviors and the adhesive film itself (especially changes in humidity perpendicular to the grain).

In contrast, splices mechanically fastened with screws have lower stiffness, and joint failure occurs in the wood splices via tension perpendicular to the grain. The bearing capacity of a joint depends on many factors. This is especially true for the tensile strength of wood perpendicular to the grain; 
the number of natural imperfections (grown wood has more imperfections than LVL boards); overall dimensions and, in particular, dimensions of splices; number, arrangement, size, and quality of the screws. The joint with mechanical fasteners shows a higher ductility than that of glued joints, which is significant from the point of view of safety. The joint shows noticeable deformations before failure occurs and can acoustically warn of the approaching maximum load-bearing capacity. This leaves space for possible repair or replacement of the joint. Combined joints (gluing and screws, mechanical fasteners) include the advantages of both methods of joining, when screws can additionally create sufficient pressure for the glued joint in the phase of its solidification and hardening. This can lead to a more even distribution of the adhesive and the formation of a uniform surface, which must be checked to avoid an uneven film adhesive. This phase of jointing is very sensitive and can largely affect the load-bearing capacity. The number of tests was limited due to time and capacity reasons, so it will be necessary to continue verifications of the above hypotheses with a larger series of tests, including the creation of relevant numerical models verified by standard design approaches and literature, and validated by new physical tests.

Author Contributions: Conceptualization, K.V. and A.L.; methodology, D.M., A.L. and K.V.; formal analysis, D.M. and A.L.; test preparation and processing, K.V., D.M. and O.S.; data evaluation, K.V. and D.M.; writing-original draft preparation, K.V., D.M. and A.L.; writing-review and editing, K.V. All authors have read and agreed on the published version of the manuscript.

Funding: This research received no external funding.

Conflicts of Interest: The authors declare no conflict of interest.

\section{References}

1. Gustafsson, J.; Serrano, E.; Aicher, S.; Johansson, C.J. Strength Design Equation for Glued-in Rods; International RILEM Symposium Joints in Timber Structures: Stuttgart, Germany, 2001.

2. Jung, H.-J.; Song, Y.-J.; Lee, I.-H.; Hong, S.-I. Moment Resistance Performance Evaluation of Larch Glulam Joints using GFRP-reinforced Laminated Plate and GFRP Rod. J. Korean Wood Sci. Technol. 2016, 44, 40-47. [CrossRef]

3. Guan, Z.W. Structural Behavior of Glued Bolt Joints Using FRP; WCTE; Presses Polytechniques et Universitaires Romandes: Lousanne, Switzerland, 1998; Volume 98, pp. 265-272.

4. Vašek, M.; Mikeš, K. The metal joints for the space timber structures, the non-linear behavior. In Proceedings of the 5th World Conference on Timber Engineering, Montreux, Switzerland, 17-20 August 1998.

5. Lokaj, A.; Klajmonová, K. Round timber joints exposed to static and dynamic loading. Wood Res. 2014, $59,439-448$.

6. Rumlová, J.; Fojtik, R. The Timber Tie Beam: The Analysis of Spatial Framework Joint. Procedia Eng. 2015, 114, 132-139. [CrossRef]

7. Jasieńko, J.; Nowak, T.P. Solid timber beams strengthened with steel plates-Experimental studies. In Construction and Building Materials; Elsevier Science: Amsterdam, The Netherlands, 2014; Volume 63, pp. 81-88.

8. Li, Y.; Cao, S.; Xue, J. Analysis on mechanical behavior of dovetail mortise-tenon joints with looseness in traditional timber buildings. Struct. Eng. Mech. 2016, 60, 903-921. [CrossRef]

9. Serrano, E. On the Mechanical Behavior of Test Specimens for Wood-Adhesive Bonds, Report TVSM-3063; Division of Structural Mechanics, Lund University: Lund, Sweden, 2002.

10. Noguchi, M.; Komatsu, K. Estimation of stiffness and strength in timber knee joints with adhesive and verification by experiment. J. Wood Sci. 2006, 52, 411-421. [CrossRef]

11. Cameron, F.A.; Pizzi, A. Effect of excessive pretreatment of pine timber with CCA wood preservatives on the bond quality of PRF and TRF wood adhesives. Holz Roh- Werkst. 1985, 43, 149-151. [CrossRef]

12. Stoeckel, F.; Konnerth, J.; Gindl-Altmutter, W. Mechanical properties of adhesives for bonding wood-A review. Int. J. Adhes. Adhes. 2013, 45, 32-41. [CrossRef]

13. Pizzo, B.; Lavisci, P.; Misani, C.; Triboulot, P. The compatibility of structural adhesives with wood. Holz RohWerkst. 2003, 61, 288-290. [CrossRef] 
14. Eurocode 5, 2006: Design of Timber Structures-Part 1-1: General-Common Rules and Rules for Buildings (European Standard).

15. CSN 73 1702, 2007: Design of Timber Structures-General Rules for Buildings (Czech National Standard).

Publisher's Note: MDPI stays neutral with regard to jurisdictional claims in published maps and institutional affiliations.

(C) 2020 by the authors. Licensee MDPI, Basel, Switzerland. This article is an open access article distributed under the terms and conditions of the Creative Commons Attribution (CC BY) license (http://creativecommons.org/licenses/by/4.0/). 